\title{
$\mathrm{PH} \mathbf{9 9}$ obata
}

a debate Patrocinio, mecenazgo, crowdfunding ¿compromiso social o marketing interesado?

| coordina Ana Isabel Velasco Rebollo

\section{Ninguna fuente de financiación es neutral: ética y mecenazgo}

David Ruiz Ruiz | gestor cultural y editor del blog Economía y Cultura

URL de la contribución <www.iaph.es/revistaph/index.php/revistaph/article/view/4573>

Reflexionar en torno al papel que el mecenazgo juega o ha de jugar en la cultura en nuestro entorno, nos lleva, en primera instancia, a varios lugares comunes:

1. Desde finales de la pasada década se ha producido una importante reducción de recursos públicos destinados a la cultura.

2. Se ha intentado potenciar el papel del mecenazgo cultural (aunque los resultados distan mucho de ser óptimos, como podemos comprobar, entre otros, en RUBIO AROSTEGUI; VILLARROYA PLANAS, 2019).

3. Este se ha convertido para casi todo el sector en una fuente de financiación tan necesaria como asumida y legítima.

Estas tesis han de entenderse en el marco de un debate en torno a la cultura y a los bienes culturales y su especificidad. Se trata, en definitiva, del papel que han de desempeñar los poderes públicos; si estos han de intervenir el mercado para protegerlos y cómo. La propia Constitución Española establece que "los poderes públicos promoverán y tutelarán el acceso a la cultura, a la que todos tienen derecho" (art. 44.1), pero no ahonda en ello. Como señala Cejudo (2017: 2) "este mandato puede llevarse a efecto con distintos sistemas de financiación, unos basados en aportaciones sustanciales de las arcas públicas, otros en aportaciones menores". Pero, como hemos indicado, la realidad es bien diferente.

Recurrimos, para contextualizar, a Salvatore Settis, arqueólogo e historiador del arte italiano autor del ya clásico Italia Spa. L'assalto al patrimonio culturale (2002) y que fue nombrado director de la Cátedra del Prado en el curso 2010-11, que nos manifestaba una tendencia ocurrida en Italia (extrapolable a España) en la que se pasa de la consideración del patrimonio cultural como un elemento identitario y que los poderes públicos han de proteger (incluso recogido explícitamente en las propias constituciones) a un elemento sujeto a las relaciones económicas. Así, transitamos por una fase cultural determinada por el "triunfo" (hegemonía) del capitalismo en la que se llega casi a una religión del capital, triunfo del mercado y divinización del mismo: Todo lo que es capital, mercado y moneda vale, son los valores verdaderos y todo lo demás es un error. Es el fin de la democracia tal y como la habíamos entendido (SETTIS, 2010: 1 y 2).

En ese contexto es en el que debemos ver el mecenazgo: "En un mundo dominado por una economía que prioriza el interés particular sobre el interés común, en un mundo cuyo ethos está dominado por el dinero y la acumulación de riqueza, ¿sigue siendo el mecenazgo una parcela aparte, que se mueve por estímulos propios, inmune a dejarse arrastrar por la mercantilización?" (CAMPS, 2016). La respuesta a esa pregunta supone un problema ético que alcanza y supera las urgencias de financiación de los proyectos, bienes y patrimonio cultural. Por tanto, "si algo tiene que reprochar la ética al mecenazgo, será o bien que se utilice para encubrir algo que pervierta el objetivo primordial del patrocinio, o bien

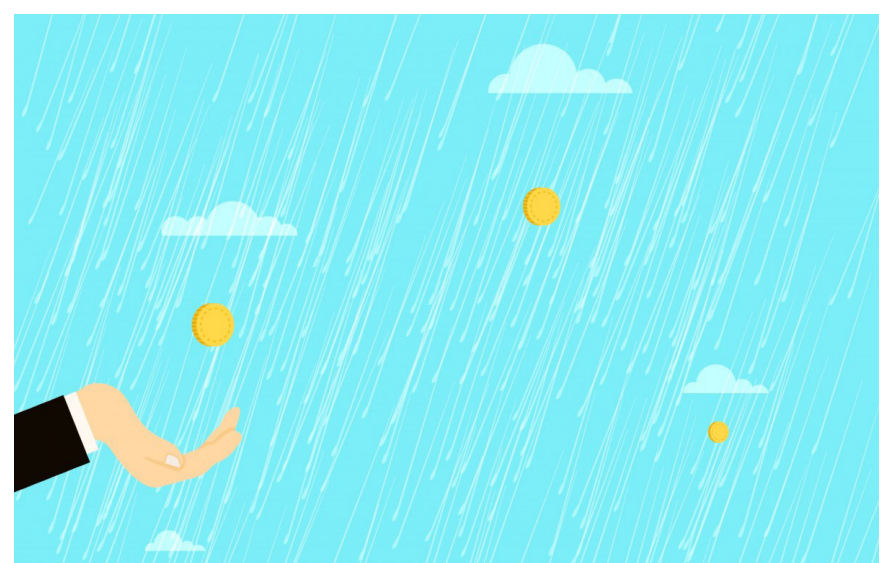


que se sirva de unos medios o dé lugar a unas consecuencias inaceptables o incoherentes con los principios éticos (...) Las élites empresariales, al invertir en arte (...), transforman el capital económico de sus empresas en capital cultural, con el objetivo no tanto de proteger la cultura o la educación como de satisfacer sus propios fines y el interés de sus compañías" (CAMPS, 2016).

Frente al mecenazgo en sentido estricto, nos encontramos con el auge del fenómeno denominado micromecenazgo, crowdfunding o mecenazgo ciudadano. Tiene también una dimensión ética y no sólo debe ser atendido como fuente de financiación -principal o complementaria- (CEJUDO, 2017: 1). En él entran en juego las relaciones entre consumidor, productor, cultura y mecenas. Podemos diferenciar los comportamientos de los individuos como consumidores o como ciudadanos y cuestionarnos el paternalismo del Estado y los poderes públicos.

Es más, cabría preguntarse, hasta desde un punto de vista pragmático y atendiendo a los incentivos fiscales al mecenazgo, si son justos o no. El donante recibe exenciones fiscales porque invierte en bienes públicos a los que el Estado y los poderes públicos están obligados a proteger. Este hecho merma los ingresos del Estado vía impuestos. Es decir, parece que se conculca el principio redistribuidor del Estado por cuanto un donante decide dónde va su dinero y no el propio Estado redistribuidor. Sus impuestos sirven para financiar sus deseos. ¿O estamos sugiriendo un mayor ejercicio de paternalismo desde el Estado?

Creemos, para finalizar, que estas cuestiones no tienen un carácter dilemático. Seguramente encontremos un lugar legítimo a la participación del ciudadano como micro mecenas en la gestión y tutela del patrimonio en algún punto situado entre el paternalismo de los poderes públicos, la mayoría de edad ciudadana y rehuir los riesgos de caer en una falacia ad populum (no tiene por qué darse A, aunque la mayoría afirme A). Tal vez la solución resida en el equilibrio entre los deberes de los poderes públicos y la actitud y posicionamiento ciudadano.
Podríamos decir que, en lo relativo a la financiación de la cultura y la protección de los bienes culturales, la mayoría de edad de la ciudadanía debe incluir el término medio que equilibre la financiación, la soberanía y el mandato a los poderes públicos. Nada más tentador que terminar una reflexión sobre patrimonio y ética recurriendo a Kant y Aristóteles.

\section{BIBLIOGRAFÍA}

- CAMPS, V. (2016) Ética y mecenazgo. En CALVO SERRALLER, F. de; CAMPS, V.; MARINA, J. A.; PARDO, J. L. Los cauces de la generosidad. Ensayos históricocríticos sobre los fundamentos del mecenazgo [en línea]. Barcelona: Fundación Arte y Mecenazgo, 2016 (Cuaderno Arte y Mecenazgo; 04) <https://coleccion.caixaforum.com/ documents/10180/2956113/Los-cauces-de-la-generosidad_ Cuaderno-04.pdf/7ae73912-efc7-d68d-a7b5-f9ae1d0dae4b> [Consulta: 10/01/2020]

- CEJUDO CÓRDOBA, R. (2017) La participación del público en el coste de la oferta cultural: argumentos éticos para el debate. Arbor: Ciencia, pensamiento y cultura, vol. 193, n. ${ }^{\circ}$ 784, abril-junio 2017 <http://arbor.revistas.csic.es/index.php/ arbor/article/download/2195/2998> [Consulta: 10/01/2020]

- CEJUDO, R. (2017) Argumentos culturales para la responsabilidad social empresarial. Recerca: revista de pensament $i$ analisi, n. ${ }^{\circ} 21,2017$ pp. 107-130 <http://www.erevistes.uji.es/index.php/recerca/article/download/2324/2199> [Consulta: 10/01/2020]

- RUBIO AROSTEGUI, J.A.; VILLARROYA PLANAS, A. (2019) El papel del mecenazgo en la política española. Propuestas para reconfigurar su papel en la crisis en las artes y la industria cultural [en línea]. [Madrid]: Ministerio de Cultura y Deporte (trabajo realizado por Fundación Alternativas para Unidad Cultura y Mecenazgo), marzo 2019 <http://www.culturaydeporte. gob.es/dam/jcr:fc0e64ed-7450-4878-a854-0e39e52bfc75/ papeldelmecenazgo.pdf> [Consulta: 10/01/2020]

- SETTIS, S. (2010) Entrevista a Salvatore Settis, director de la Cátedra del Prado 2010. En Hoyesarte.com, 12 nov. 2010 <https://www.youtube.com/watch?v=KJgdX5mzPMs> [Consul ta: $10 / 01 / 2020]$

- SETTIS, S. (2010) Conversación con el Prof. Salvatore Settis. En Museo Nacional del Prado, 1 sept. $2010<$ https://www. youtube.com/watch?v=zEsfCRWIKyl> [Consulta: 10/01/2020] 